\title{
Synoptic climatology and recent climate trends at Lake El'gygytgyn
}

\author{
M. Nolan ${ }^{1}$, E. N. Cassano ${ }^{2}$, and J. J. Cassano ${ }^{2}$ \\ ${ }^{1}$ University of Colorado at Boulder, Cooperative Institute for Research in Environmental Sciences, 216 UCB, \\ Boulder, CO 80309, USA \\ ${ }^{2}$ University of Alaska Fairbanks, Institute of Northern Engineering, Fairbanks, AK 99775, USA \\ Correspondence to: M. Nolan (matt2013@drmattnolan.org), E. N. Cassano (ecassano@ciresmail.colorado.edu), \\ and J. J. Cassano (john.cassano@colorado.edu)
}

Received: 2 March 2012 - Published in Clim. Past Discuss.: 23 April 2012

Revised: 3 January 2013 - Accepted: 1 February 2013 - Published: 19 June 2013

\begin{abstract}
We developed a synoptic climatology for Lake El'gygytgyn, Chukotka Russia, and explored modern climate trends affecting air temperatures there to aid in paleoclimate reconstructions of a 3.6 million-year-old sediment core taken from the lake. Our self-organized mapping (SOM) approach identified 35 synoptic weather patterns, based on sea level pressure, that span the range of synoptic patterns influencing the study domain over the 1961-2009 NCEP/NCAR analysis period. We found strong seasonality in modern weather patterns, with summer weather primarily characterized by weak low pressure systems over the Arctic Ocean or Siberia and winter weather primarily characterized by strong high pressure over the Arctic Ocean and strong low pressure in the Pacific Ocean. In general, the primary source of variation in air temperatures came from the dominant patterns in each season, which we identify in the text, and nearly all of the dominant weather patterns here have shown increasing temperatures. We found that nearly all of the warming in mean annual temperature over the past $50 \mathrm{yr}\left(\right.$ about $3^{\circ} \mathrm{C}$ ) occurred during sub-freezing conditions on either side of summer (that is, spring and fall). Here we found that the most summer-like weather patterns (low pressures to the north) in the shoulder seasons were responsible for much of the change. Finally, we compared the warmest $15 \mathrm{yr}$ of the record (1995-2009) to the coolest (1961-1975) and found that changes in thermodynamics of weather were about 3 to 300 times more important than changes in frequency of weather patterns in controlling temperature variations during spring and fall, respectively. That is, in the modern record, general warming (local or advected) is more important by orders of magnitude than changes in storm tracks in controlling air temperature at Lake El'gygytgyn. We conclude with a discussion of how
\end{abstract}

these results may be relevant to the paleoclimate reconstruction efforts and how this relevancy could be tested further.

\section{Introduction}

Our overarching goal in this work is to begin relating local weather to modern climate at Lake El'gygytgyn, Chukotka, Russia, to facilitate paleoclimate reconstructions of a 3.6 million-year-old core extracted there in 2009 . We used the self-organized mapping (SOM) technique applied to the National Center for Environmental Prediction/National Center for Atmospheric Research (NCEP/NCAR) Reanalysis data (subsequently referred to as NNR) (Kalnay et al., 1996) for the time period 1961-2009 to understand the modern synoptic climatology and its recent trends here. The physical characteristics of the lake, lake ice dynamics, core extraction, and interpretations of prior cores are all well described in a series of papers (Layer, 2000; Nolan et al., 2002; Melles et al., 2005, 2007; Brigham-Grette et al., 2007; Cherapanova et al., 2007; Glushkova and Smirnov, 2007; Minyuk et al., 2007; Nolan and Brigham-Grette, 2007; Juschus et al., 2011). In brief, the lake is about $12 \mathrm{~km}$ wide, $175 \mathrm{~m}$ deep, lies inside an $18 \mathrm{~km}$ wide crater, has never been glaciated, has a mean annual temperature of about $-10^{\circ} \mathrm{C}$, and annual precipitation of about $20 \mathrm{~cm}$ water equivalent. The SOM technique (Kohonen, 2001) applied to synoptic climatology and reanalysis data is also well described (Kohonen, 2001; Reusch et al., 2005; E. N. Cassano et al., 2006; J. J. Cassano et al., 2006; Schuenemann and Cassano, 2010), and our work here closely follows our use of SOMs in prior work (Cassano et al., 2011). This paper also draws 
heavily from a companion paper in this special issue (Nolan, 2013) which compares measurements from a local automated weather station (AWS) that we had running from 20022008 to the NNR fields of air temperature, precipitation, and barometric pressure, and this information will not be duplicated here. Based on our prior comparisons of NNR air temperature with National Weather Service stations throughout Alaska (Cassano et al., 2011) and with our local AWS at Lake El'gygytgyn (Nolan, 2013), we believe that NNR air temperature represents reality well at Lake El'gygtgyn and have therefore used these data to analyze daily weather here without further reservation. Our specific goals in this paper are to understand the modern synoptic climate (1961-2009), determine which weather patterns bring warmer/colder air to the region, help explain the large rise in mean annual air temperature seen within the NNR record here over the past $20 \mathrm{yr}$ (Nolan and Brigham-Grette, 2007; Nolan, 2013), and discuss how to relate these results to paleoclimate proxies and analyses.

The SOM technique is used in this work to characterize the synoptic climatology of the area of study and to relate the local temperature at Lake El'gygytgyn to the broaderscale synoptic circulation. The analysis data and study domain used in the current study are the same as were used in Cassano et al. (2011). The reader is referred there for specific details on our methods and parameter choices, though a short synopsis of those items and the methodology is given here. The SOM technique employs a neural network algorithm that uses unsupervised learning to determine generalized patterns in data. This technique reduces the dimensions of large datasets by grouping similar data records together and organizing them into a two-dimensional array, referred to as a map, reducing large datasets into a more easily interpreted form. The mode in which SOMs are used here can be most directly compared to cluster analysis but, unlike some other clustering methods, it does not need a priori decisions on data distribution. There are no assumptions made as to the structure of the final clusters; the SOM will put more (less) classes in areas of higher (lower) data density while spanning the range of patterns representative of the input dataset. For the work presented in this paper, daily sea level pressure (SLP) data from the NNR (1961-2009) reanalysis datasets were used to train the SOM to find the archetypical patterns that represent the weather patterns that influence the area of study, and the final map is organized such that similar synoptic patterns are located in the same portion of the map. Numerous papers have shown the SOM technique to robustly identify the synoptic weather patterns that affect a given area (Reusch et al., 2005; E. N. Cassano et al., 2006; J. J. Cassano et al., 2006; Lynch et al., 2006; Finnis et al., 2009; Schuenemann and Cassano, 2010). The technical details of the methodology of the SOM algorithm are fully described in Kohonen (2001) and an overview of its applications to synoptic climatology is given in Hewiston and Crane (2002) and Cassano et al. (2007).
In the current work, a SOM with 35 patterns ( 7 columns by 5 rows) was used for analyses. SOMs of this size have been found suitable for synoptic climatology studies since this size SOM compactly displays the major circulation patterns and storm tracks (Hewiston and Crane, 2002; Cassano et al., 2007). Once the patterns have been identified, each day of data is compared with each pattern to find which pattern it most closely matches (Reusch et al., 2005; E. N. Cassano et al., 2006; J. J. Cassano et al., 2006; Lynch et al., 2006; Finnis et al., 2009; Schuenemann and Cassano, 2010). This list of dates associated with each pattern (the daily lookup table) can then be used in a variety of statistical ways. For example, annual or seasonal frequencies of each of the 35 patterns can be tracked with time, or another daily lookup table of air temperature anomalies can be used to determine which patterns tend to bring the warmest or coldest weather. Figure 1 presents the master SOM from our prior work, reproduced here for convenience, which contains the 35 SLP patterns that we found characterize the domain, along with labels 135 corresponding to their identification in the text.

SLP was chosen as the basis for the representation of the circulation patterns that impact the area around Lake El'gygytgyn and to focus on the relationship between the near-surface circulation and the weather observed at the surface. The SLP data were further processed by calculating the anomaly (by subtracting the daily mean from the grid point values for that same day) and these data were used for the SOM training. This was done because the SLP gradients, rather than the absolute values of SLP, are responsible for determining the near-surface circulation (Cassano et al., 2011). The study domain used here has been used for several of our study sites but selected with this study in mind. A domain in which Lake El'gygytgyn is centrally located would be optimal. However, the flow impacting the area is still well represented within the current domain size. The orientation of the isobars in the Lake E area (or lack thereof in cases of weak flow) is clearly giving us a picture of not only the localized flow, but that of the flow upstream, allowing an analysis of the relationship between the temperature at the local scale and the large-scale circulation.

\section{SOM analysis of modern air temperature anomalies}

We calculated mean air temperature anomalies for each SOM node to determine which patterns are responsible for bringing the warmest and coldest variations in local weather and then assessed whether these results matched our intuition about the dynamics responsible for those anomalies. To do this, we first calculated mean air temperature anomalies for each SOM node by reducing daily temperatures (Fig. 2a) to have zero-means by subtracting the mean temperature on, for example, 1 January from each of the 481 Januaries in the study period (Fig. 2a, first column) to arrive at a daily temperature anomaly for that day (Fig. 2b). Using the daily SOM 


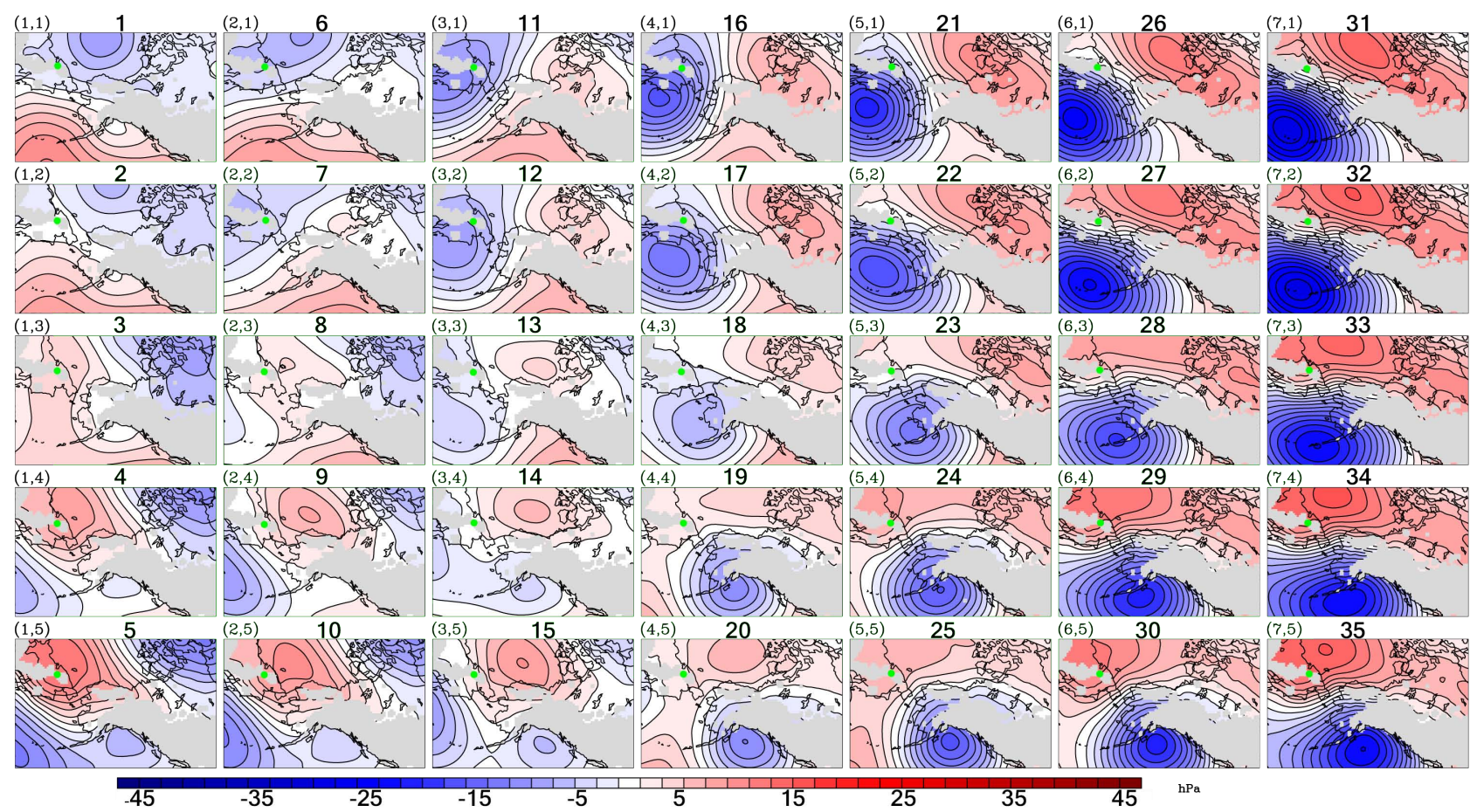

Fig. 1. SOM patterns used in this study. The sea-level pressure-patterns here capture the full range of weather experienced within the domain over the past $50 \mathrm{yr}$, as described in the text. Each weather pattern can be identified with the single number above it or the (column, row) notation used in prior work; e.g., pattern 26 and $(\mathrm{c} 3, \mathrm{r} 2)$ are the same. Green circles show approximate location of Lake El'gygytgyn.

lookup table and the NNR $2 \mathrm{~m}$ temperature anomaly from the grid point closest to Lake El'gygytgyn from 1961-2009, we found the average daily temperature anomaly for each SOM pattern (Fig. 3a).

The close linkages between $2 \mathrm{~m}$ air temperature anomalies and circulation patterns are evident by observing the average spatial $2 \mathrm{~m}$ temperature anomaly over the entire area of study for each pattern identified by the SOM (Fig. 3b). For example, in pattern 31 (row 1, column 7), there is an Aleutian low centered near the tip of the island chain with high pressure located in the Beaufort Sea. The distribution of temperature anomalies for this pattern show warm temperature anomalies over much of Siberia and Alaska in the southerly flow ahead of the low, and cold temperature anomalies in northwestern Canada in the northerly flow ahead of the high pressure system. In almost all cases of the 35 patterns, as expected, southerly flow ahead of low pressure systems moving west-to-east brings warm weather ahead of their approach; and the converse, northerly flow ahead of a high pressure system, brings cold temperature anomalies to that area. Given that our local AWS data closely track the NNR $2 \mathrm{~m}$ air temperatures (Nolan, 2013), and that the model's air temperatures and sea level pressure patterns closely track as we have just described, we believe the air temperature analyses we perform through this paper are appropriate for allowing a better understanding of modern local climate and its trends, and hope that this will be of use to the paleoclimate reconstruction effort. Our methods will hopefully make clear what teleconnections exist between Lake El'gygytgyn and the surrounding domain and how to exploit them, such as through comparisons with other paleoclimate sites within the domain. In the remainder of this section we give examples of how to make use of Figs. 1 and $3 b$ by describing some of the larger trends; these are the key figures to the paper, and are worth having handy while reading the rest of the manuscript.

As with all SOM analyses, conclusions made from an analysis product such as Fig. 3 is done by comparison with the SOM master plot in Fig. 1. For example, the warmest anomaly found in Fig. $3 \mathrm{a}, 4.9^{\circ} \mathrm{C}$, occurs at pattern 26 (row 1, column 6). According to Fig. 1, pattern 26 is characterized by a strong low pressure in the Bering Sea, south of Lake El'gygytgyn, and a strong high pressure in the Beaufort Sea to the north and east of the lake. In this situation, warm air from the south and east is funneled to the northwest between these two systems. According to Fig. 3b, this pattern tends also to warm western Alaska with the same air, but cools western Canada by bringing cold Arctic Ocean air downwards on the eastern side of the high pressure system.

The patterns that bring the warmest temperature anomalies to Lake El'gygytgyn also affect large regions of eastern Siberia and western Alaska. In general, these are westward and northwestward shifted Aleutian lows (patterns 16, 21, 26, and 31; right side of row 1 in Figs. 1 and 3b) bringing air from the south and east. Other patterns that bring weaker 

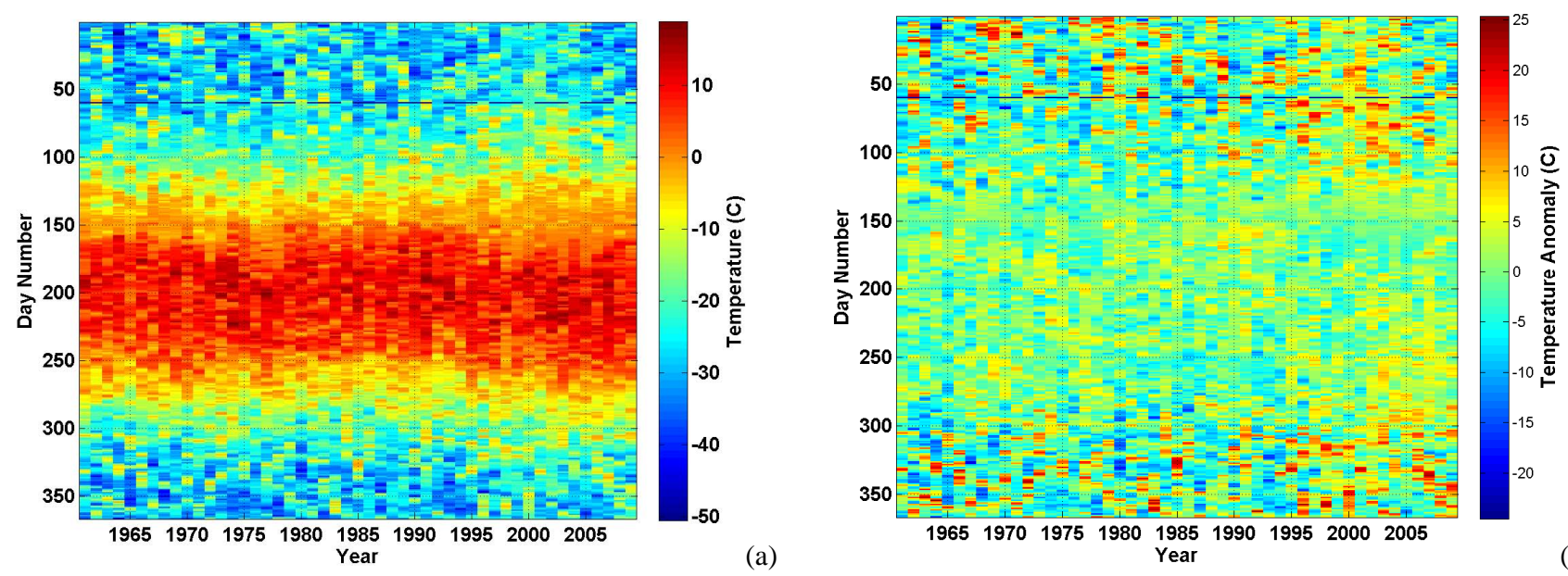

(b)
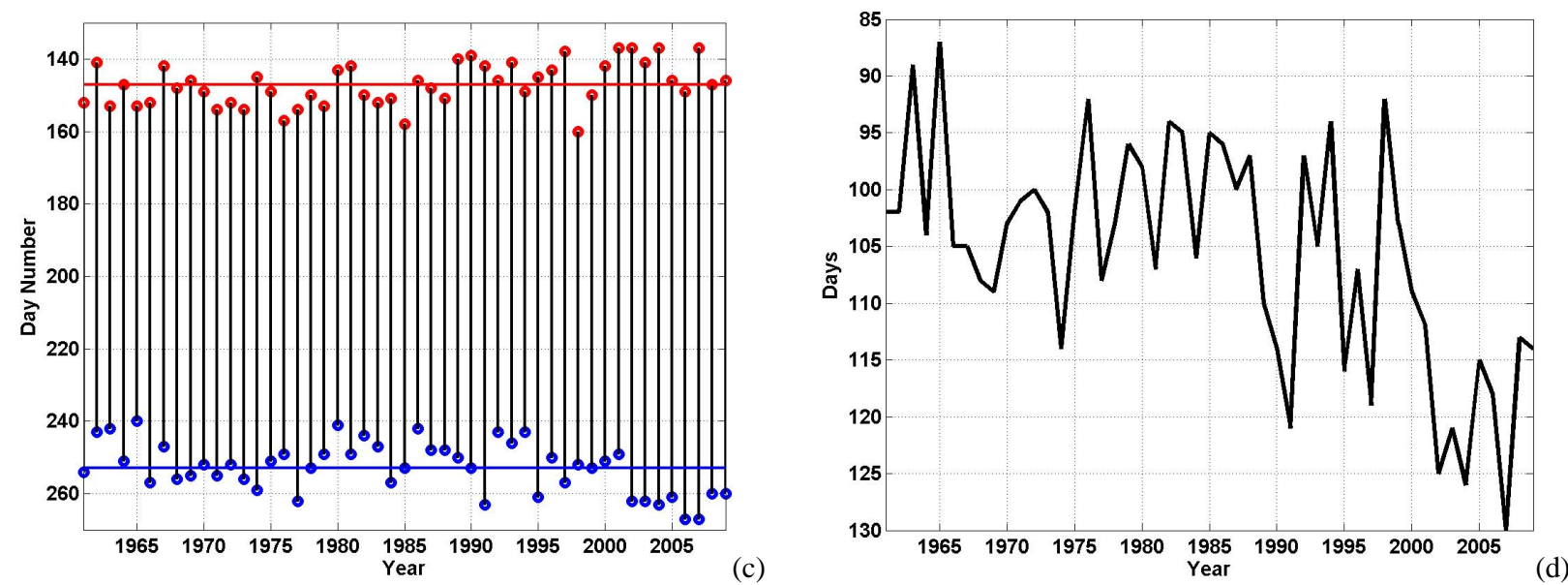

Fig. 2. Daily $2 \mathrm{~m}$ NCEP air temperatures (a) and anomalies (b) at Lake El'gygytgyn. The anomalies, as described in the text, remove seasonal trends (e.g., summer is warmer than winter) and each daily anomaly can be compared to the weather pattern on that day (Fig. 1) to create pattern-averaged anomalies (Fig. 3a). Much of this paper deals with the warming (more yellows and reds) seen in spring and fall beginning around 1990 in (a). (c) Thaw season start (red) and end (blue) dates for each year along with means (horizontal lines). (d) Length of thaw season in days.

warm temperature anomalies are those with weaker pressure systems in similar locations, bringing air from the south and east towards the northwest (patterns 10,15, and 20). Though the flows into the lake are similar to these two clusters of patterns, the impact on Alaska is different as the latter tend to also bring cold air from the north and east to Alaska, since for these patterns the high pressure in the Arctic Ocean is located further west, putting Alaska in the northerly flow ahead of the system. Thus, paleoclimatologists should be aware that the teleconnections in air temperatures between sites is dependent on the weather systems that dominate at that time.

The coldest temperature anomalies for the Lake El'gygytgyn region are associated with moderate low pressure systems centered in the Gulf of Alaska with broad high pressure over eastern Siberia and the Beaufort/Chukchi Seas (patterns 23-25 and 28-30). These patterns tend to bring air to the lake from the east-northeast over the Arctic
Ocean. When these patterns occur during the winter, the air advected into eastern Siberia likely passes over sea ice rather than open water and thus stays cold. When there is open water present, this may warm the air somewhat before reaching the Lake El'gygytgyn area. These patterns tend to cool all of Beringia, while warming Canada.

\section{Seasonal air temperature trends in SOM patterns}

To expand upon our prior work, which used calendar months to define seasons, here we explored the use of positive and negative degree-days (PDD and NDD) to define seasons and trends. Degree-days are defined by simply summing daily average air temperatures in ${ }^{\circ} \mathrm{C}$. The motivation for using degree-days to define the freezing and thawing seasons is that nearly all biological and physical processes of interest to our core interpretations are controlled strongly by the 


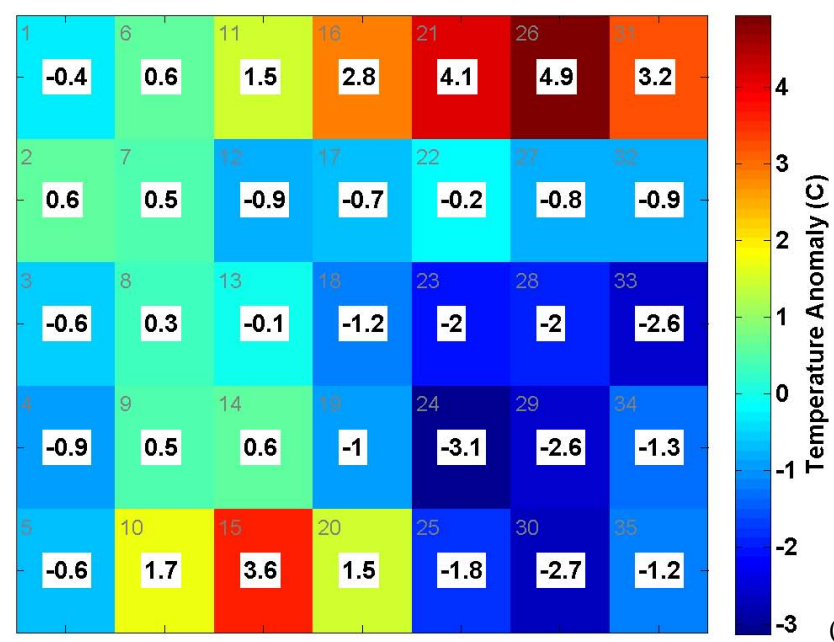

(a)

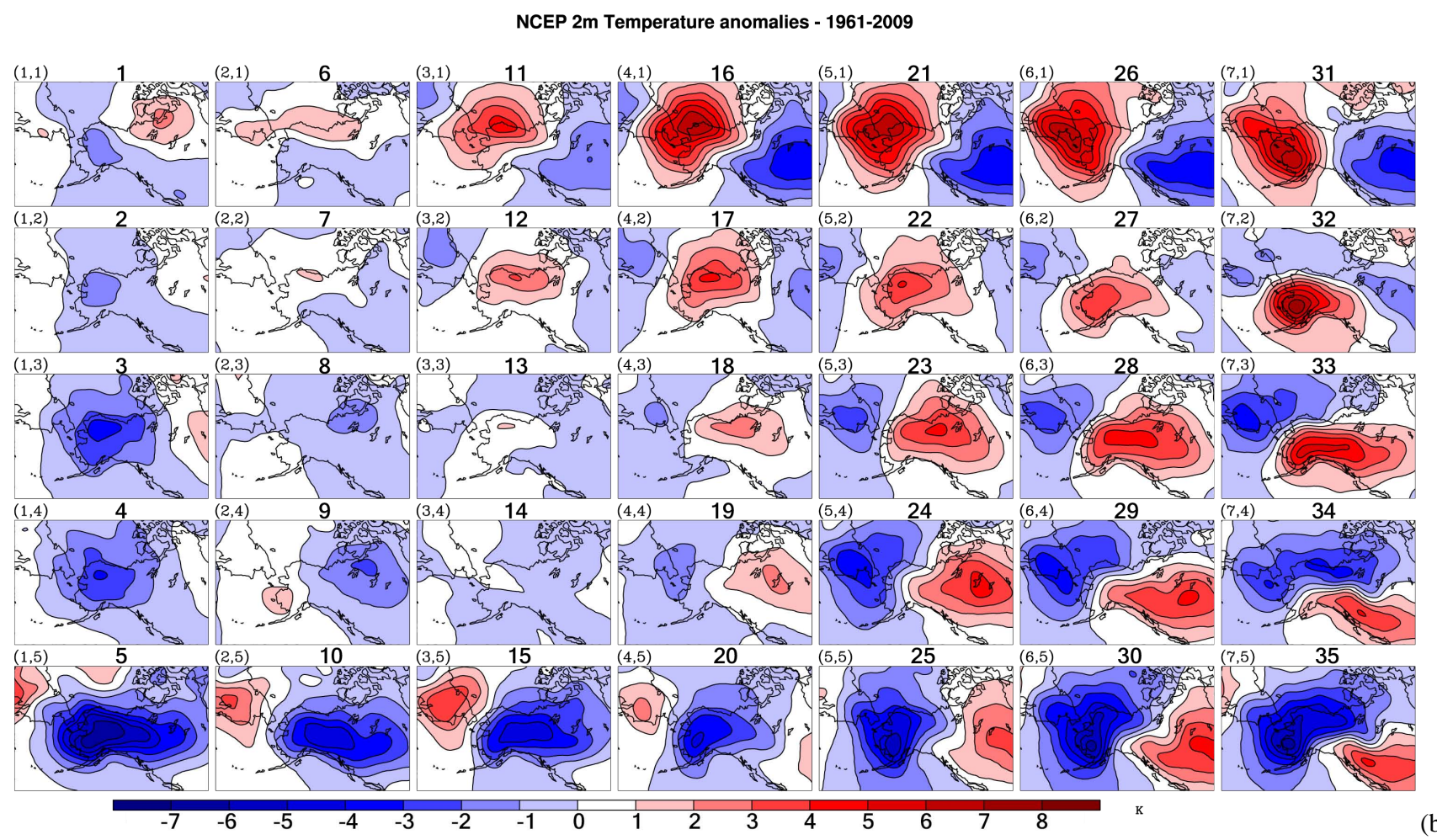

Fig. 3. (a) Pattern-averaged temperature anomaly for each SOM node at the lake. For example, over the study period, on any day that pattern 26 was dominating, one could expect a $4.9^{\circ} \mathrm{C}$ warmer air temperature than the mean for that day of the year. Thus, if the frequency of pattern 26 increased over time, one would expect the mean annual air temperature to rise too. (b) Temperature anomalies for each SOM node across the entire domain. These plots aggregate the analysis of (a) (at Lake El'gygytgyn) for each grid point in the domain. The plots should aid substantially in understanding teleconnections between the lake and the surrounding domain. For example, pattern 26 that brings such anomalously warm air to the lake also brings cold air to Canada, whereas pattern 5 brings cold air nearly everywhere. Figure 1 and (b) are referred to constantly throughout the text, so having them close at hand or printed out separately is advised by the authors, as there is a lot of information packed into them.

liquid/solid transition of water, whether that be lake ice dynamics, soil erosion, vegetation growth, or aquatic biologic productivity. Further, degree-days themselves are especially useful metrics for determining lake ice thickness and timing of melt, and by tracking the transitions from freezing to thawin conditions whereby the air temperature crosses the $0{ }^{\circ} \mathrm{C}$ threshold (which also separates PDD from NDD), we can also track changes in seasonal lengths, something not possible with calendar definitions of seasons. 

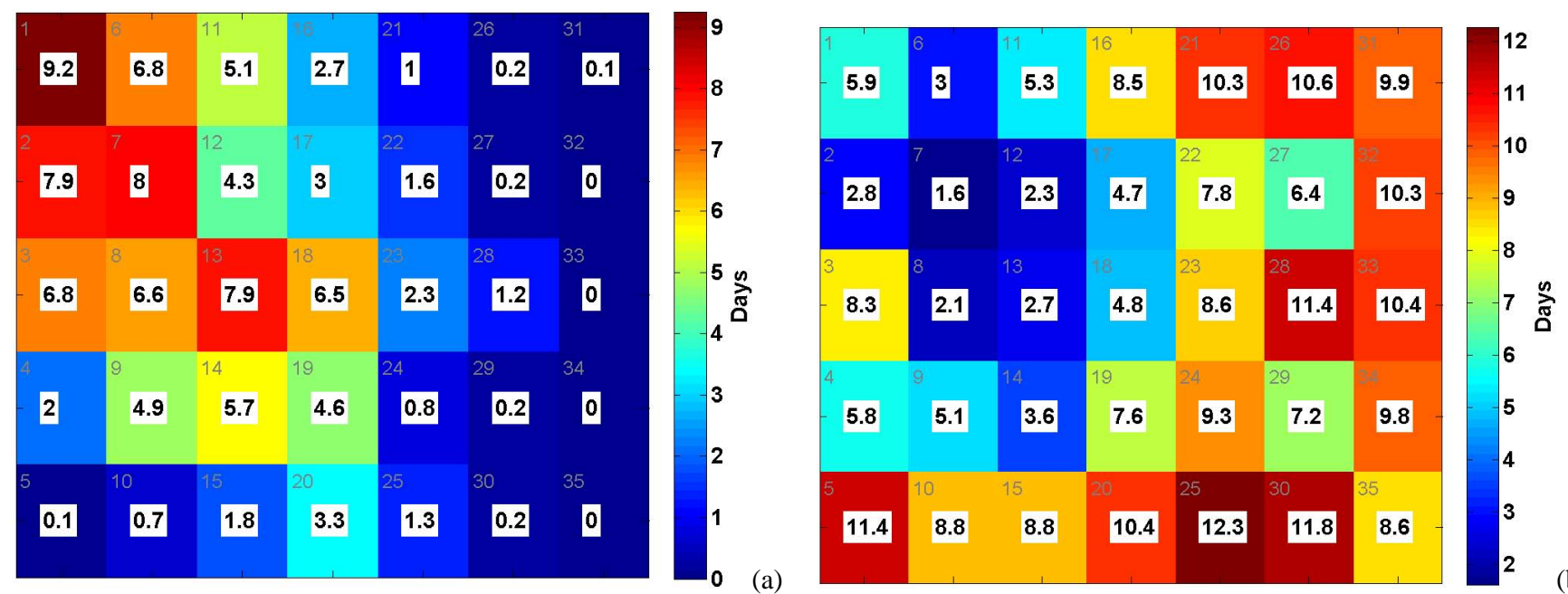

Fig. 4. SOM frequencies in average days per year (1961-2009) during the freezing (a) and thawing (b) seasons. For example, the right-most column in (b) shows that 49 days of the year are controlled by this type of weather, which Fig. 1 indicates as having strong Aleutian lows. These daily averages sum to 365 days. In (a) and (b), color indicates the same information as the numbers, but this is not the case in the subsequent figures.

To begin, we start with only two seasons, a freezing and thawing season, and then later expand this to consider spring and fall dynamics. We calculated the length of these seasons by fitting a sinusoid through the daily air temperature data and noting where it crossed $0^{\circ} \mathrm{C}$. The issue is that many years do not have a smooth transition across $0^{\circ} \mathrm{C}$ in spring or fall, with spikes of up to several days that cross it. We visually inspected each annual record to confirm that the sinusoid was capturing reality well. The dates of the start and end of the thaw season are shown in Fig. $2 \mathrm{c}$ and the length of thaw season in Fig. 2d. As can be seen, there is a strong trend towards increasing the length of the thaw season since at least 1998. The post 2000 mean, 119 days, is more than 2 standard deviations of the prior mean of 103 days. Our related work has shown the increase in MAAT (mean annual air temperature) and winter warming began in the late 1980s, and a large focus of this paper is determining the synoptic causes for all these changes in air temperatures.

We found strong seasonal trends in synoptic weather patterns, in terms of degree-days and wind direction, which may be of relevance to core proxies. Here we have calculated NDD and PDD without regard to the season length above, treating each day independently of the rest based on whether it is above or below $0{ }^{\circ} \mathrm{C}$. Figure $4 \mathrm{a}$ and $\mathrm{b}$ plot the frequency of each weather pattern, in average number of days per year over 1961-2009, for the long-term freeze and thaw seasons defined above simply by air temperature; summing the text numbers in Fig. 4 yields the average length of freeze-thaw seasons in days (107 thaw-days, 258 freeze-days). These figures show that freeze season is long and the thaw season is short, and that patterns with strong low-pressure centers over the Aleutian Islands with high pressure in the Beaufort and Chukchi Seas (right side of Fig. 1) dominate almost half the year on average. These patterns tend to bring cold air from the east and north to the lake from areas dominated by snow-covered land or ice-covered ocean but rarely open ocean since these patterns primarily occur during the winter months (Cassano et al., 2011). The seasonal differences are strong, as almost any weather pattern can be expected for a few days in winter, but in summer the observed patterns are largely those lacking a strong low pressure in the Pacific. The patterns that do occur in the summer are characterized by low pressure systems much weaker than in winter and broad high pressures systems, which usually tend to bring warm air from ice-free areas of the Pacific from the south and west. What is not clear from Fig. 4 is the degree-day magnitude of these events. That is, one cannot make the claim that because a pattern is more frequent that it is more important to accumulating degree-days or to trends in PDD or NDD. For example, a pattern that occurs frequently but has a daily average degreedays near zero would contribute little to the annual total of degree-days, while a less frequent pattern with large positive or negative degree-days, but that occurs less frequently, would contribute more to the annual total of degree-days.

While in general the bulk of the degree-days come from the most frequent patterns, some patterns stand out in magnitude. Figure 5a and $\mathrm{b}$ reveals which SOM patterns are most responsible for NDD and PDD. Here we find that NDD (4802 degree-days) is about 7 times higher than PDD (675 degree-days) by adding the text numbers in Fig. 5, meaning that summers are cool but winters cold, and thus winter (and winter weather patterns) dominates the annual degree-day signal (see Nolan, 2013 for more detail on this).

Comparison of Figs. 4 and 5 reveals a major benefit of characterizing weather patterns by degree-days, in that degree-days are the product of frequency and temperature, 

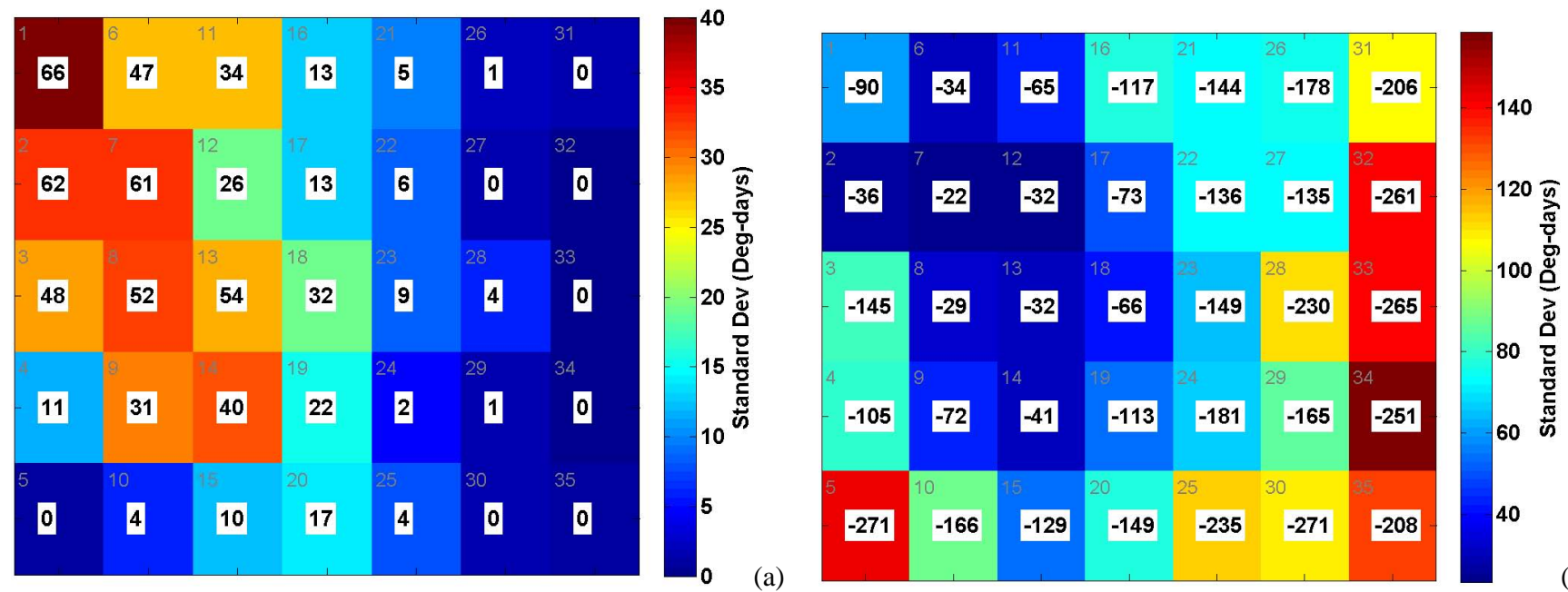

(b)

Fig. 5. Mean positive (a) and negative (b) degree-days for each SOM cell over 1961-2009 at Lake El'gygytgyn. Numbers are mean value and colors are standard deviation. For example, patterns 5 and 30 have the same negative degree-days (-271) but pattern 5 has about $50 \%$ more variation, indicating that it is more likely to be responsible for inter-annual variations; these two patterns alone total nearly the same as the total positive degree-days for all patterns (a). Pattern 34 alone has shown a 2- $\sigma$ variation in range that is nearly equal to all positive degreedays, indicating that winters have a higher sensitivity and demonstrated capability for affecting annual means and inter-annual variability in the modern record.

giving a sense of the actual magnitude of impact of a given pattern on seasonal temperature trends. The differences between frequency and magnitude can be quite large, especially in winter. For example, patterns 21 and 32 both have the same average frequency (Fig. 4), but differ by 107 degree-days (which is $15 \%$ of the total PDD) in Fig. 5. Large discrepancies can be seen for several other patterns. In summer we find that frequencies and degree-days each paint essentially the same picture, though minor differences are evident on the scale of several degree-days.

Color in Fig. 5 represents the standard deviation of degreedays for each pattern. From this analysis it is shown that some patterns have a much higher variability than others and therefore have a greater influence on the inter-annual variability in lake weather. These weather patterns with high standard deviations tend also to have the highest means and thus exert the strongest controls on their respective seasons as well as the strongest inter-annual variability. That is, inter-annual consistency drives seasonal processes, but interannual inconsistency drives variations and trends, and some patterns seem responsible for both.

The most important weather pattern in summer is represented by pattern 1 , characterized by a low pressure center north of the lake, with a mean PDD contribution of 66 and a standard deviation of about 40 degree-days. This variation is not large in an absolute sense, but it is larger than the standard deviation of annual PDD over the entire record (Nolan, 2013), indicating that this pattern alone could account for nearly all inter-annual variations in summer PDD.

In winter we see that patterns 5 and 30 occur with about the same frequency and magnitude, but that pattern 5 has
$50 \%$ higher variation and thus more influence on whether a particular winter is warmer or colder. In this case, these two patterns alone account for about $10 \%$ (542 degree-days) of the mean annual NDD, with a combined 2-sigma variation of about \pm 500 degree-days. Pattern 34 alone can vary from +45 to -547 degree-days (mean $\pm 2-\sigma$ ). Patterns 32, 33, and 35 also show high magnitudes coupled with high variability. These patterns are the real weather makers at Lake El'gygytgyn, at least in the modern environment.

\section{Interannual air temperature trends in SOM patterns}

The largest trend in air temperature over the modern record is the large increase in mean annual air temperature (MAAT) beginning in the late-1980s, from a 1961-1994 mean of $-12.8^{\circ} \mathrm{C}$ to a $1995-2009$ mean of $-9.1^{\circ} \mathrm{C}$ (see Fig. 5 in Nolan, 2013), which we explained as being due to winter warming, with mean annual NDD rising from -5043 to -4340 degree-days over that same time. In this section we explore the changes in weather patterns that accompanied this change in MAAT using further degree-days analysis combined with the SOM technique.

Figure $2 \mathrm{a}$ and $\mathrm{b}$ show daily NNR $2 \mathrm{~m}$ air temperature and air temperature anomaly for the entire record (19612009), giving us a visual impression of those trends, especially in terms of defining spring and fall transitional seasons. In Fig. 2a, we can see beginning in the late-1980s that daily spring temperatures rose considerably (more yellows and oranges) in March (i.e., days 60 to 90 ), and also that peak winter temperatures were warmer as well (more light blues, yellows and oranges); the period 1995-2001 was especially 

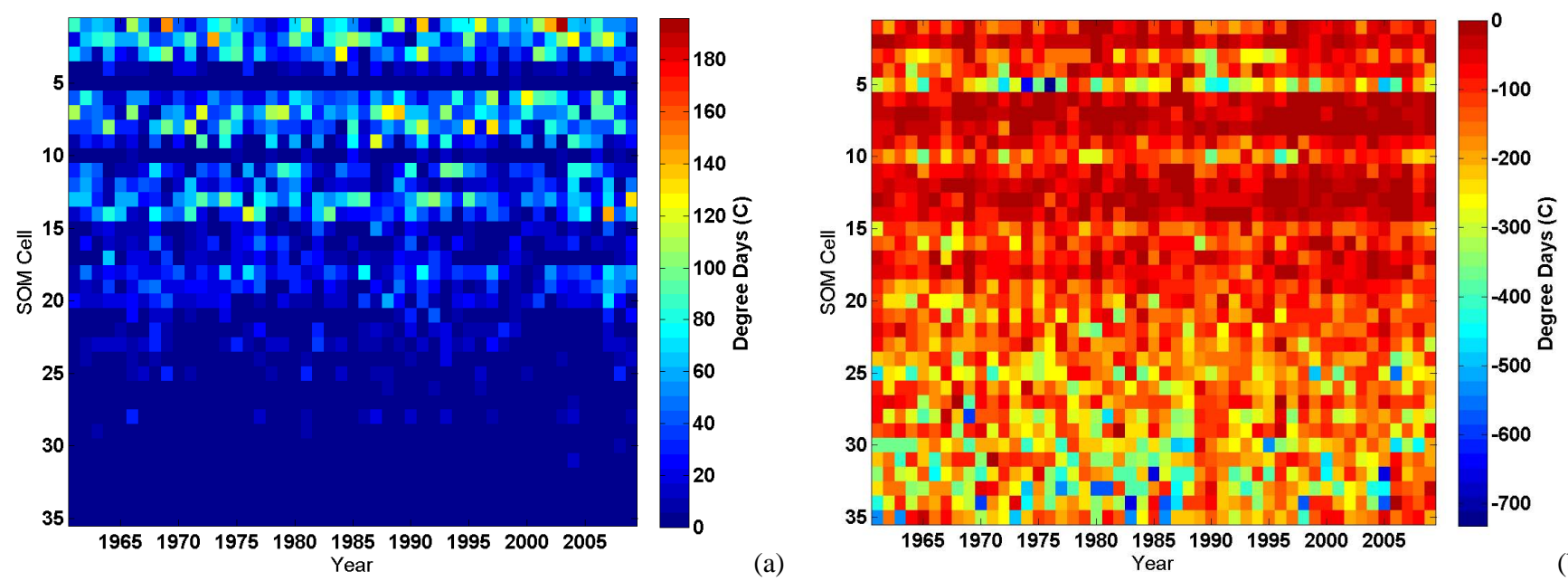

Fig. 6. Positive (a) and negative (b) degree-days by SOM pattern for each year of the NCEP record used here. These plots show which weather patterns most strongly influence freeze or thaw seasons. For example, patterns 30-35 dominate freezing but have little influence on thawing, and these patterns show high variability, indicating they are responsible for much of the interannual variability. The plots also show trends. For example, patterns 11-14 have been getting warmer in the freeze season - more dark reds in (b) - as well as warmer in the thaw season - less dark blue in (a). The causes for individual warm or cold years (Fig. 8) can also be pinned to individual patterns using these plots.

notable for this. Fall also became warmer at this time, extending through 2009. Early summer, about day 150, seems to have gotten a bit cooler in the last $15 \mathrm{yr}$ (more yellows and oranges than previous $15 \mathrm{yr}$ ), with late summers getting warmer (more deep reds). During this time, there was little trend in PDD, with means changing from +666 to +700 , indicating that the changes largely balance out in terms of PDD. Given this visual inspection and the analysis of Fig. 4, it seems that the calendar month definition of spring and fall (MarchApril-May - MAM - and September-October-November SON) are reasonable fits for exploring frequency and magnitude changes at the lake, but obviously cannot help us with changes in season lengths.

By plotting degree-days for each SOM pattern for each year, we can explore the causes of warm and cold years. Figure 6a and $\mathrm{b}$ do this for PDD and NDD, respectively. These plots also give a graphic representation of which patterns dominate which season; for example, patterns 20-35 clearly contribute little to summer heating, but dominate winter cooling. In Fig. 6a, we see that patterns 1, 3, and 8 largely explain the highest PDDs on record in 1991. Similarly, an unusually high PDD in pattern 1 in 2002 and 2003 largely balance cooling seen in some of the others, and in 2004 a record high pattern 2 dominated moderate warming of other cells to create the record high annual PDD. In the freezing seasons (essentially fall, winter, and spring), patterns 5 and 30-35 show high inter-annual variability, as also seen in Fig. 5, with most patterns showing some warming over time. Note again that the magnitude of variation is much higher in the freeze season than in the thaw season, indicating that below-freezing weather has the most potential for changing annual means at Lake El'gygytgyn.

We analyzed trends in degree-days for each of the 35 patterns by fitting linear trend lines through their annual degreedays from 19610-2009. An example of this analysis is presented in Fig. 7a for pattern 6. Here we see a strong rise in degree-days over time, a seemingly characteristic difference between the first and last $15 \mathrm{yr}$ of the record, and a switch from being a contributor to NDD to PDD (that is, it crossed the zero degree-day mark from negative to positive). Figure $7 \mathrm{~b}$ shows the magnitude of change over the analysis period (that is, the difference in trend line endpoints such as in Fig. 7a) and therefore the general trend shown in Fig. 7a for each pattern. For example, pattern 6 has a dark red color indicating in 2009 of about 40 degree-days (PDD) and a text value of 60, indicating that in 1961 it had an average -20 degree-days (NDD); note that the text value is for the trend line endpoint differences, not the individual 2009 and 1961 annual differences, so the actual 1961 value cannot be reconstructed with Fig. 7b.

Using Fig. 7b, we find that nearly all patterns have shown warming over this time; some patterns have changed from contributing to PDD from NDD, and some patterns emerge as driving overall change. The general picture that emerges here is that the patterns that are showing the most warming are not those characteristic of the freezing season (right side in Fig. 1), but those characteristic of thawing season (upper left in Fig. 1) that occur during the freezing season. However, the thaw season is not getting warmer, but rather the freezingseason occurrence of typical thaw-season patterns are getting warmer and, perhaps more importantly, these patterns 

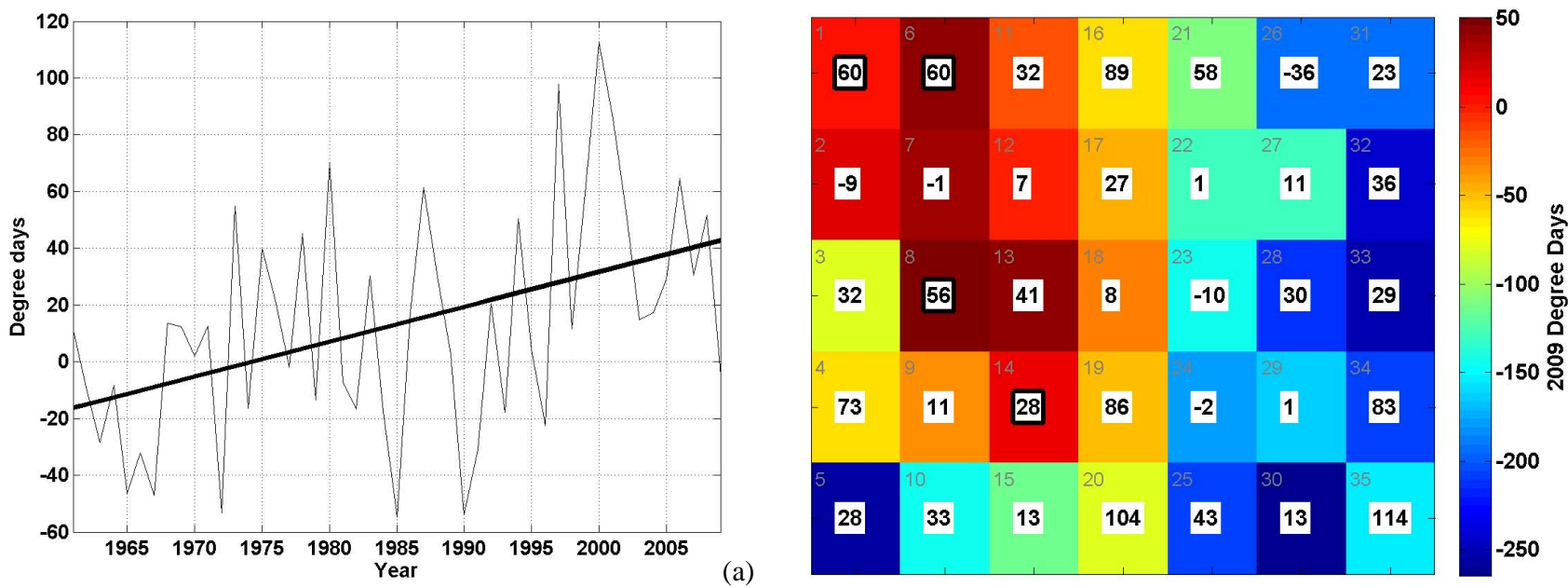

(b)

Fig. 7. (a) Degree-days (thin line) 1961-2009 for SOM pattern 6 with trend line (thick line). Here, pattern 6 can be seen getting warmer over time. Here we use the linear trend line only to smooth the noise by using its end-points in (b) and we are not indicating the actual trend is linear. Later in the paper, we explore the change in means of the first 15 and last $15 \mathrm{yr}$ of record (e.g., Fig. 9). (b) Change in degree-days 1961-2009 for all SOM patterns at Lake El'gygytgyn. The numbers are the change in trend-line endpoints, as in (a), and the colors are the degreedays for each pattern in 2009, so that one can estimate the value in 1961 using the numbers. Positive values indicate warming. Here heavy boxes surround those patterns, like pattern 6 from (a), that change from negative to positive degree-days over time.

are often crossing or approaching the transition from being net NDD-contributors to net PDD-contributors. Winteronly patterns, such as the Aleutian lows, are also getting warmer, but, with a few exceptions, lower in magnitude and lower in percentage change in degree-days than the summerlike patterns. Perhaps more importantly for our paleoclimate purposes, none of these freezing-season patterns is close to crossing the 0 degree-day threshold. Thus, it seems that the warmest of the winter patterns are experiencing the most change, and these are of course found at the transitions between winter and summer - that is, fall and spring, as we saw in Fig. 2.

Analysis of annual trends in seasonal degree-days further confirms that much of the recent warming can be explained by changes in spring and fall. Here we defined winter, spring, summer, and fall by the standard Northern Hemisphere 3 month intervals of DJF, MAM, JJA, and SON, respectively (where the letters are the initial of each month). Figure 8 shows that most of the change in fall and spring appears to have occurred starting about 1995, when mean negative degree-days appear to have increased by $286 \mathrm{DD}$ and $339 \mathrm{DD}$, respectively, more than 2 standard deviations above their prior means. The remaining NDD from the winter season (DJF) shows essentially no change in mean compared to the prior period, and over the last $10 \mathrm{yr}$ of record PDD has a cooling trend, indicating that nearly all MAAT increase is being driven by comparatively larger warming trends in springs and falls. Further, nearly all of the trend in meanannual PDD after 1994 (+34 degree-days) can be explained by warming falls (thin black line emerging from zero in early 1990s), which increased in means by +31 DD after 1994.

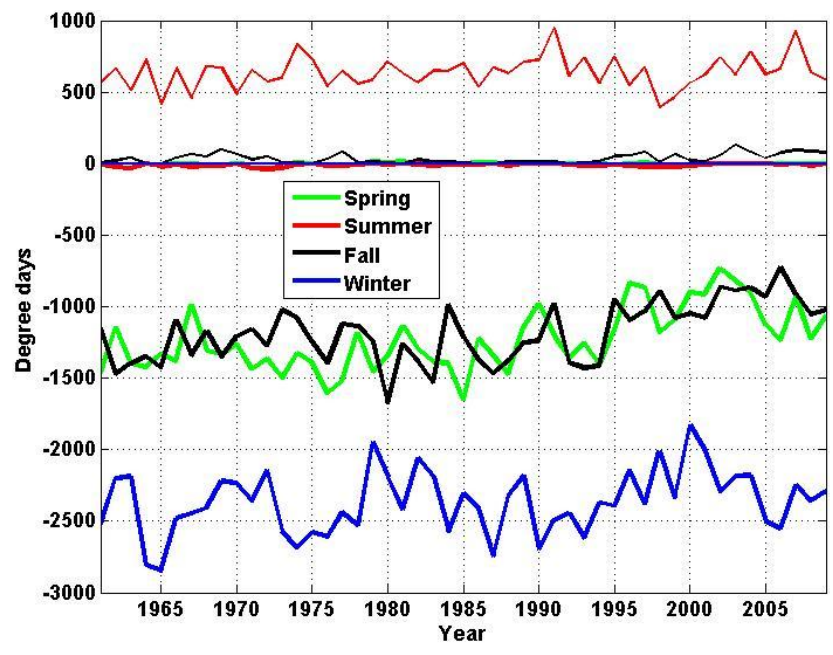

Fig. 8. Seasonal variations of PDD (thin lines) and NDD (thick lines). The greatest changes during the freezing season occurs in fall and spring beginning in the mid-1990s. Similarly, the biggest changes in thaw season occur in fall about the same time (thin black line emerging from 0 ).

\section{Interdecadal air temperature trends in SOM patterns}

Given that weather here seems to have changed around 1995, and that we have $15 \mathrm{yr}$ of such data (1995-2009) following this pivotal year that approach climate time-scales, we chose to compare this period to the first $15 \mathrm{yr}$ (1961-1975) of the record. The degree-day trend during both of these periods is near zero, suggesting that these are periods of relatively stable, but different, climate. Some of the intervening years 
show signs of being intermediate between the two states, further influencing our choice of comparison periods. We calculated degree-days for each period, pattern, and season by taking the mean of the 15 seasonal values calculated by summing daily values within that season for each year. Then we differenced the values between periods for each season, plotting the results in Fig. 9 with numbers indicating the change in degree-days and colors representing the magnitude of degree-days in the first period to visualize the seasonal importance of each pattern. For example, in Fig. 9a one can see which patterns are most representative of winter by the blue colors and summers by the dark red colors, with all of the positive numbers indicating warming over this period, and the highest numbers representing patterns that show the most warming.

Fall and spring again emerge as the drivers of annual change in the modern record. The total annual change was +886 degree-days and per season was $+31,+338,+318$, and +199 degree-days for the JJA, MAM, SON, and DJF periods, respectively. Note that the spring and fall periods are characterized by sub-freezing temperatures, so these total degreedays changes are over $95 \%$ due to changes in NDD.

Interesting trends for individual weather patterns are also apparent within each season (Fig. 9b-e). In spring, the biggest changes are found in those patterns that are characteristic of spring (as denoted by green and blue color in Fig. 9b), which are intermediate between summer and winter patterns characterized by weak low pressure centers near the Aleutians and even weaker high pressure centers in the Arctic Ocean. Almost all patterns in spring show warming as well. Most of the change in summer is coming from those patterns that are most frequent (as seen in Fig. 4), as we described previously, but several summer patterns actually show slight cooling (Fig. 9c). The largest changes in autumn (Fig. 9d) are from those patterns typical of summer, characterized by low pressure in the Beaufort and Chukchi Seas (upper left corner of Fig. 1). In fall, these patterns still bring freezing air temperatures, but the air is warmer now than earlier in the record, suggesting that fall is becoming more like summer. Typical winter patterns that occur in fall (right side of Fig. 1) characterized by strong Aleutian low pressure centers also show warming in fall, as does pattern 16 , which has a strong low pressure center south of Chukotka. Thus, in fall, patterns bringing winds from nearly every direction show warming, though the summer-like pattern 1 shows the highest increase. In winter (Fig. 9e), the bulk of the change appears to be coming from patterns that do not typically dominate the winter climate. That is, other than pattern 35 (a strong low pressure in the Gulf of Alaska and the strongest high pressure in the Arctic Ocean), the typical winter patterns show relatively little change. The biggest changes in winter are seen in patterns characterized by high pressures over Chukotka (e.g., patterns $3-5,10)$ and those with strong low pressures over or south of Chukotka (e.g., patterns 16, 17, 21). Overall, as the degree-days numbers show, all seasons show warming, and this warming is observed in most patterns.

The trends that we see here are in general agreement with prior work. Comiso (2003), using AVHRR clear-sky satellite-temperature data, found over the time period of 1981-2000 positive temperature trends in autumn, spring, and summer. In the Lake El'gygytgyn area, the warming trends were strongest over land areas in summer and over the Beaufort and Chukchi Seas in autumn. These increases are consistent with a longer melt season (with both earlier spring melt and later autumn freezeup) also discussed in the paper. Lindsay and Zhang (2005) analyzed surface air temperatures over the Arctic Ocean from the NNR and found increases in temperatures for the Arctic basin for all four seasons, weakest in the summer. Serreze et al. (2009) also used the NNR data over the Arctic north of $70^{\circ}$ and found autumn surface temperature anomalies over the time period of 1979-2007 predominantly negative through the mid 1990s to strongly positive in the later part of the record, with less positive anomalies extending in to winter.

\section{Attribution of air temperature trends in SOM patterns}

What is the cause of the seasonal warming trends? The SOM technique can be used to investigate whether this climate shift was due to a change in frequency in weather patterns towards those that bring warm weather or whether some patterns are simply getting warmer without becoming more frequent, as we had done in prior work (Cassano et al., 2011). This SOM analysis is nearly identical to this prior work, which explored a shift in climate from 1961-1975 to 1976-1990 that strongly affected air temperatures throughout much of Alaska, just relabeled here in terms of degreedays. This shift in 1976 does not appear as strongly at Lake El'gygytgyn, if at all, and here the period 1976-1993 shows signs of being a transition between the two periods we chose for our new study. We also extend our analyses here to understand the seasonal differences in this shift. For clarity, we summarize the basic mathematics here, but the reader is referred to Cassano et al. (2011) for details. We start by calculating a mean frequency (in days per year) and a mean temperature for each pattern for each time period (19611975 and 1995-2009), calling them $F_{1 i}, F_{2 i}, T_{1 i}$, and $T_{2 i}$, respectively, where the $i$ represents each of the 35 weather patterns in the SOM. We can then calculate mean degreedays (DD) for each period for each pattern by

$\mathrm{DD}_{1}=\Sigma\left(F_{1 i} \cdot T_{1 i}\right)$,

and

$\mathrm{DD}_{2}=\Sigma\left(F_{2 i} \cdot T_{2 i}\right)$.

$F_{2}$ and $T_{2}$ can also be described as the following:

$F_{2 i}=F_{1 i}+\Delta F_{i}$, where $\Delta F_{i}=F_{2 i}-F_{1 i}$ 


\begin{tabular}{|c|c|c|c|c|c|c|}
\hline 64 & 47 & 31 & 81 & 44 & -34 & -10 \\
\hline & 7 & 12 & 17 & 22 & 27 & 32 \\
\hline-1 & 4 & 10 & 22 & -3 & 7 & 5 \\
\hline 3 & & 13 & & 23 & 28 & 33 \\
\hline 27 & 40 & 22 & 17 & 1 & 31 & -1 \\
\hline 4 & & 4 & 19 & & 29 & 34 \\
\hline 65 & 2 & 21 & 64 & 5 & 11 & 46 \\
\hline & & 15 & & 25 & 30 & 35 \\
\hline 33 & 22 & 14 & 76 & 38 & 0 & 85 \\
\hline
\end{tabular}

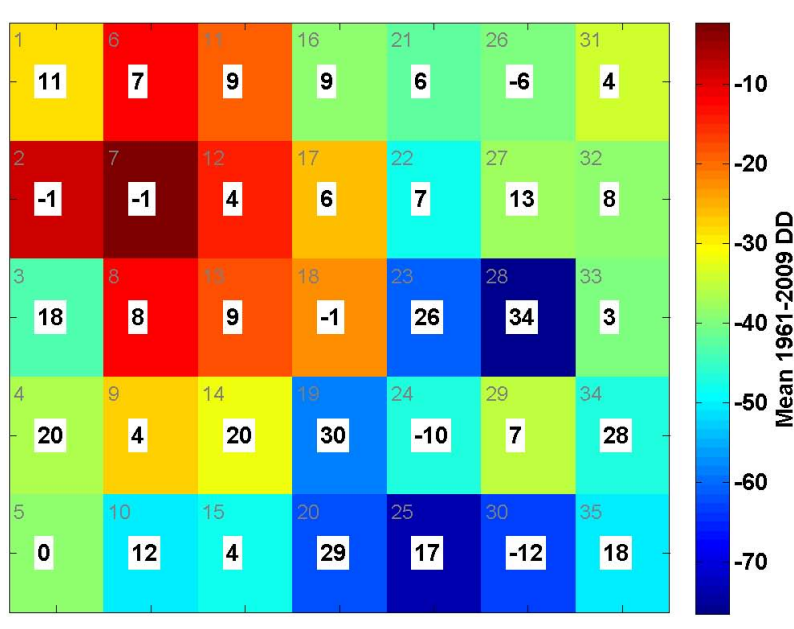

(b)

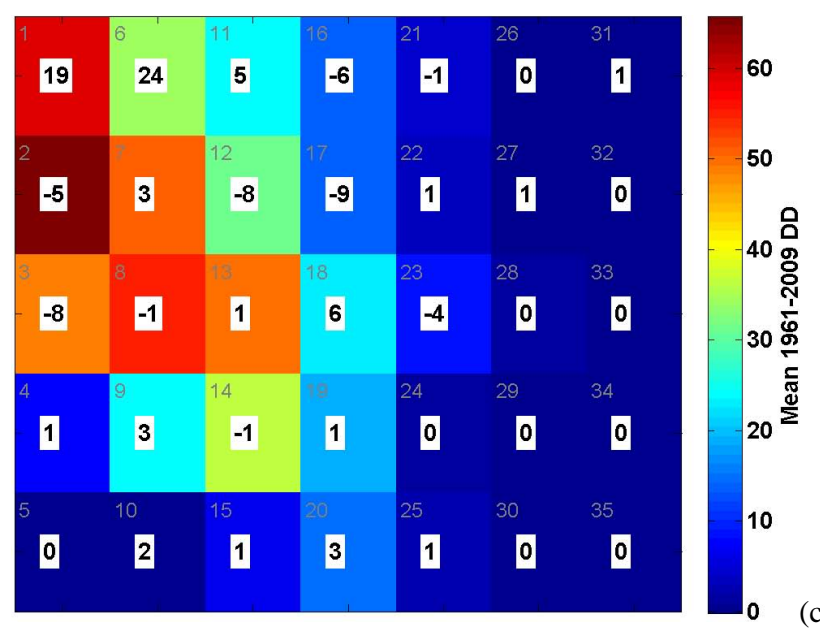

(a)

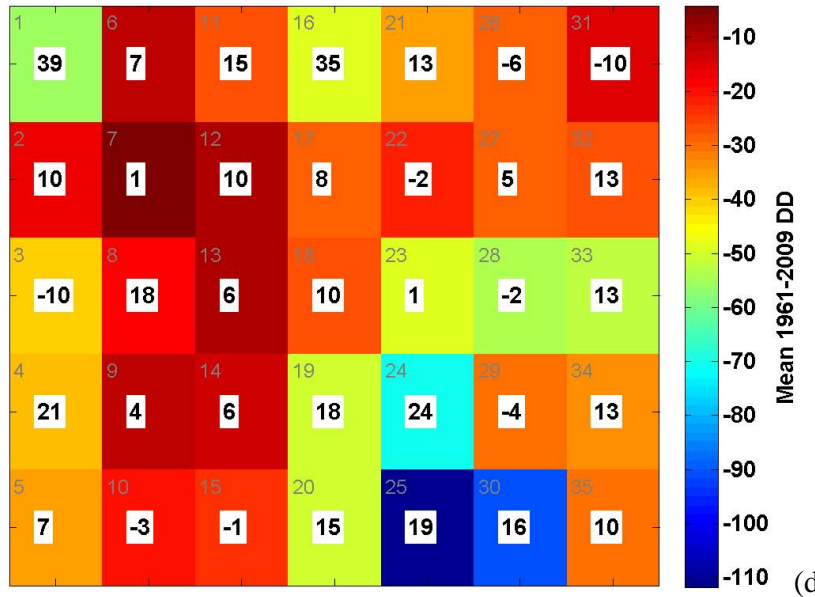

(d)

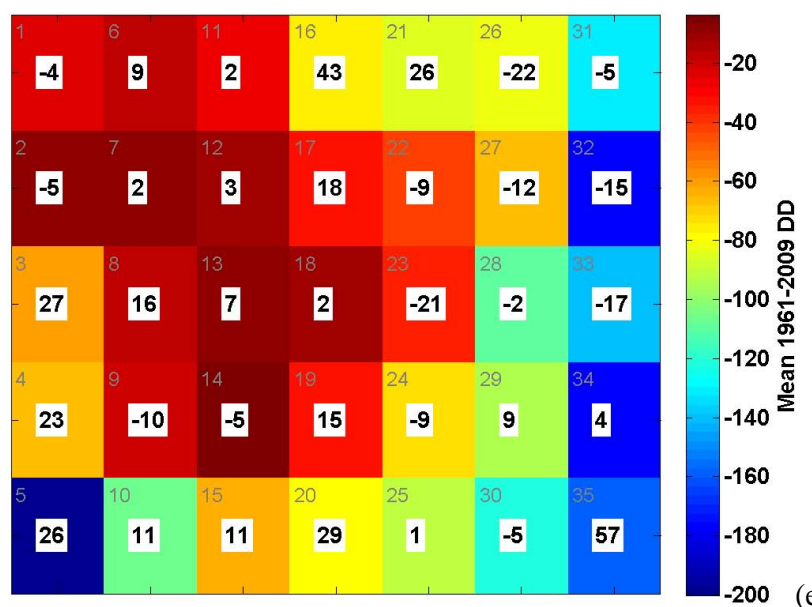

(e)

Fig. 9. (a) Annual, (b) MAM (spring), (c) JJA (summer), (d) SON (fall), and (e) DJF (winter) changes in degree-days between means of 1995-2009 and 1961-1975. Positive numbers indicate warming. Note that nearly all changes are positive. Colors indicate the mean over the entire record used so that one can get a sense of how the magnitude of change compares to the mean degree-day contribution. 
Table 1. The first three columns represent the three terms in Eq. (5). "Ratio" is the ratio of thermodynamics to frequency (that is, Term 1 divided by Term 2), $\mathrm{DD}_{2}-\mathrm{DD}_{1}$ is the change in degree-days calculated in Eq. (5) (the sum of the three Terms).

\begin{tabular}{lrrrrr}
\hline & $\begin{array}{c}\text { Thermodynamics } \\
(\text { Term 1) }\end{array}$ & $\begin{array}{r}\text { Frequency } \\
(\text { Term 2) }\end{array}$ & $\begin{array}{r}\text { Combined } \\
(\text { Term 3) }\end{array}$ & Ratio & $\mathrm{DD}_{2}-\mathrm{DD}_{1}$ \\
\hline MAM & 341.8 & -24.9 & 21.6 & 13.7 & 338.4 \\
JJA & 24.1 & 8.5 & -1.9 & 2.8 & 30.6 \\
SON & 324.3 & 1.1 & -7.9 & 294.8 & 317.5 \\
DJF & 196.9 & -33.6 & 35.6 & 5.8 & 199.1 \\
\hline Annual & 887.2 & -48.7 & 47.4 & 18.2 & 886 \\
\hline
\end{tabular}

and

$T_{2 i}=T_{1 i}+\Delta T_{i}, \quad$ where $\Delta T_{i}=T_{2 i}-T_{1 i}$.

Substituting Eqs. (3) and (4) into Eq. (2), subtracting Eq. (2) from Eq. (1), and recombining terms yields

$\mathrm{DD}_{2}-\mathrm{DD}_{1}=\Sigma\left(F_{1 i} \cdot \Delta T_{i}+T_{1 i} \cdot \Delta F_{i}+\Delta T_{i} \cdot \Delta F_{i}\right)$.

Thus, the total change in degree-days can be split between the three terms at right-hand side of Eq. (5) . The first term $\left(F_{1 i} \cdot \Delta T_{i}\right)$ represents the component of degree-days change between periods that would have occurred if the frequency of the 35 weather patterns stayed constant in time. In this case, any non-zero change would have to come from an increase in air temperature associated with that pattern, such as a warming of the source area from which the winds advect air. The second term $\left(T_{1 i} \cdot \Delta F_{i}\right)$ represents the component of total change assuming that the mean temperature of each pattern stayed constant in time and all non-zero change resulted from a change in frequency of a pattern. This would be the case if the thermodynamics of the patterns had not changed at all, but simply shifted in their relative frequencies. For example, if a pattern that typically brings warm air became more frequent at the expense of a pattern that bought cooler air (in the first period), total degree-days would increase due to this term. The final term $\left(\Delta T_{i} \cdot \Delta F_{i}\right)$ describes the impact of both frequency and thermodynamics changes that occur together, and it is usually minor compared to the other terms (Cassano et al., 2011). The result of this analysis is shown in Table 1.

Changes in thermodynamics of patterns (887.2 degreedays) dominate the annual change in degree-days, as seen in Table 1, with most of that change occurring in spring and fall (341.8 and 324.3 degree-days, respectively). Here, changes in thermodynamics range from 3 to 295 times the magnitude as changes in frequency, with the largest values in spring and fall. The clear picture that emerges from our research is that the warming observed in the NNR reanalysis mean annual air temperatures at Lake El'gygytgyn is caused by changes in thermodynamics of weather patterns, mostly in spring and fall, not from changes in their relative frequencies.

We plotted change in frequency between periods in Fig. 10 and confirm that these changes are relatively small. Here we plot the change in average number of days per period that each SOM pattern appears in the record. Most changes are 1 day or less between periods, with seasonal standard deviations (across all SOM patterns) of $0.75,0.72,0.60$, and 0.85 days for spring, summer, fall, and winter, respectively (all are zero mean change because one pattern must be replaced by another). Some of the largest changes, 1.5 to 2 days, occur in winter (Fig. 10e), but as a percentage change these are some of the lowest. Percentage change can be estimated by comparing the colors in Fig. 10, which represent pattern frequency during the first period, to the numbers, which represent the change between the two periods. For example, even though pattern 35 changed by -1.9 days in winter (Fig. 10e), given that its older frequency was about 5.8 days per year, the percentage change is about $-33 \%$. Similarly, pattern 2 increased by 0.3 days in winter, but averaged only about 0.3 days in the first period, for a change of about $100 \%$. The largest frequency changes in summer (Fig. 10c) occurred, for the most part, to those patterns that were already the most frequent. Fall (Fig. 10d) showed the lowest standard deviations in magnitudes, but some of the highest percentage changes. In general, however, frequency changes were small between these time periods and further confirm our conclusions from Table 1 that changes in frequency between patterns are not responsible for the bulk of the warming we see in degree-days during this time.

Where is this warmer air coming from? Our analysis does not distinguish between local warming and warm air advection. In our prior work looking at climate changes in Alaska around 1976 , because temperatures jumped $3-5^{\circ} \mathrm{C}$ in a year within a longer-term cooling trend, it seemed reasonable to believe that the bulk of the warm air was coming from nonlocal sources. In that case, patterns dominating change had winds from the south, suggesting the Pacific Ocean as the source. At Lake El'gygytgyn, the warming is more gradual, which may indicate that local warming is more important here than the 1976 shift in Alaska, a jump that was not observed at the lake. Based on Fig. 9 there is no clear picture of where any non-local warmer air is sourced from, but generally it is mostly from the west, south, and east. In fall, the biggest increase is in pattern 1, which has air largely coming from the west, over continental Russia, and the second 


\begin{tabular}{|c|c|c|c|c|c|c|}
\hline-1.6 & 1.4 & 1.7 & -2.6 & $\mathbf{0 . 1}$ & 3.2 & 3 \\
\hline & & 12 & 17 & 22 & 27 & \\
\hline-0.9 & 1.5 & -2.1 & -0.8 & 1.8 & 1.1 & 1.3 \\
\hline & & 13 & 18 & 23 & 28 & \\
\hline-2.1 & -1.1 & -2.2 & 0.1 & -0.1 & 0.1 & 1.5 \\
\hline-2.3 & 1.7 & 0.1 & -2.1 & ${ }^{24} 0.7$ & 0.1 & -0.4 \\
\hline & 0 & 15 & 20 & 25 & 30 & \\
\hline 0.2 & 0 & 0.3 & -1.1 & 0.2 & 1.1 & -2 \\
\hline
\end{tabular}

(a)
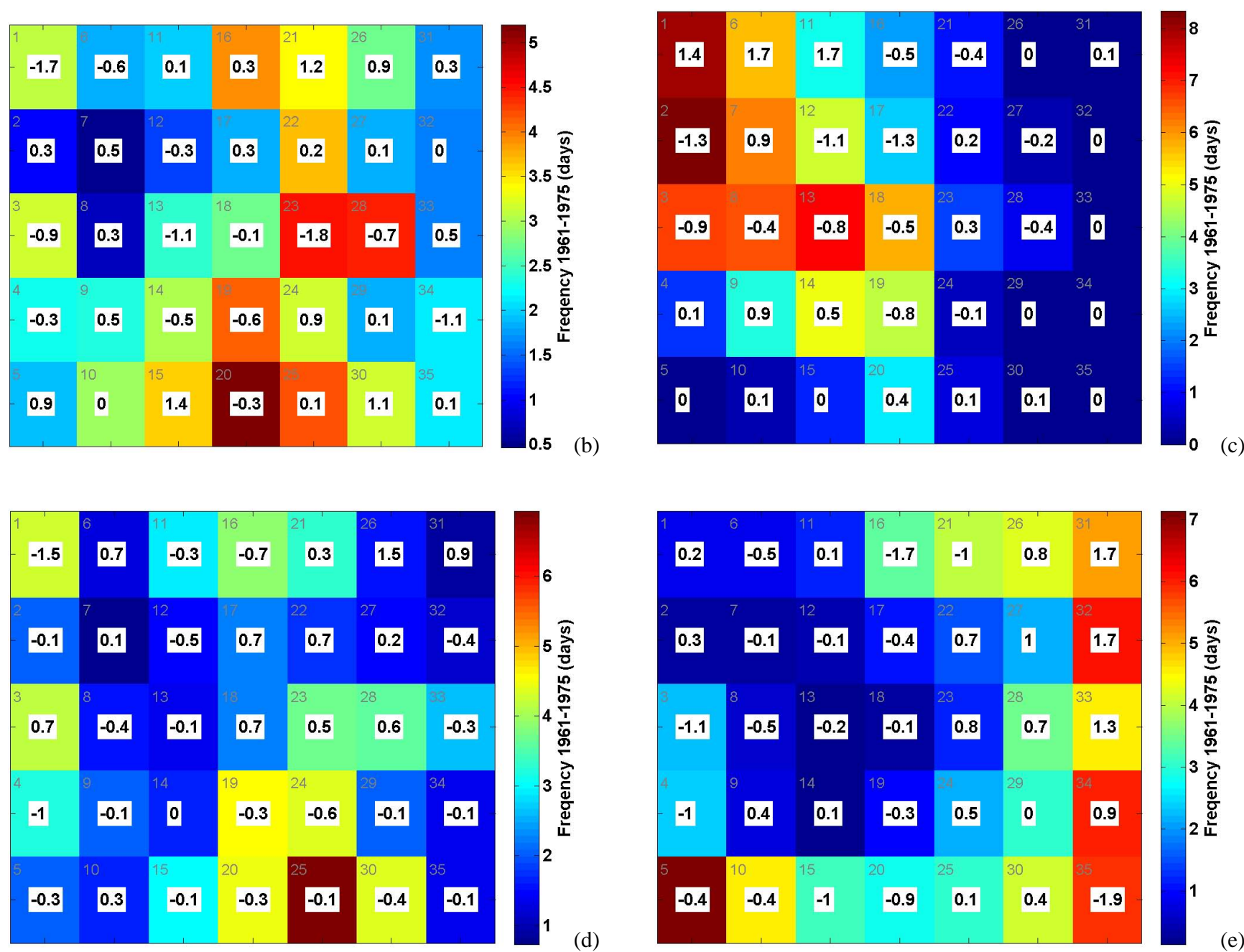

(e)

Fig. 10. (a) Annual, (b) MAM, (c) JJA, (d) SON, and (e) DJF change in average pattern frequency between means of 1995-2009 and 1961-1975. Text shows change in number of days and colors show pattern frequency during the first period to aid in assessing percentage of change. 
biggest increase is pattern 16 coming from the south, over the Bering Sea. In spring, the biggest increases come from patterns 28, 23, 19, and 20, which all tend to bring air from the east, over continental Alaska, or from the north over the Arctic Ocean. Given this, a warming Alaska or a decreasing trend in sea ice extent could have some influence on Siberia. In any case, the lake climate-trend story here seems more complicated than the 1976 story in Alaska, but the overall picture is similar in that the cause is a change in thermodynamics of patterns rather than an increase in frequency of patterns that typically bring warm air.

\section{Relevance to paleoclimate}

We believe that exploring trends in modern weather is important for paleoclimate studies because these trends give us our only direct evidence as to which patterns are most variable as well as the nature of this variability in the modern era, and most paleoclimate studies begin or center on comparison of past climate to the current one. Further, it seems a reasonable assumption for lack of other data that the current range of climate dynamics may be representative of some eras in the past. At Lake El'gygytgyn, this assumption is more likely to be true over the most recent part of the sediment core record, as the influence of plate tectonics on climate begins playing a role in the older part. Similarly, the range of weather patterns we see today may not be the same as those during glacial times, when sea level was much lower and the ocean currents much different, especially in Beringia. So our results here are likely to better inform paleoconditions during interglacials of the past $1 \mathrm{M}$ years, when circulation patterns were likely most similar to today. Unfortunately, given that much of the recent warming over the past $50 \mathrm{yr}$ has been due in part to anthropogenic influences, we cannot be certain that the dynamics we observe now are also representative of prior interglacial periods. However, given the modern instrumental period of the last $50-100 \mathrm{yr}$ is the only direct measure we have, we feel our analyses here are getting us pretty close to the best possible use of it for paleoclimate reconstructions, and we believe that this understanding of the modern environment and its trends should provide some calibration for the dynamics of modern proxies and thus hopefully improve the paleo-proxy development through comparison. Further, while magnitudes of change may or may not relate directly to paleoclimates, we believe our analyses may also be useful as a sensitivity study, if for no other reason than indicating the modern rates of change in trends are large on decadal scales.

We could test this relevancy in several ways. Figure $3 b$ indicates the teleconnections between Lake El'gygytgyn and the surrounding domain in terms of air temperatures. If a paleo-temperature reconstruction from Lake El'gygytgyn could be compared to a similar reconstruction from elsewhere in the domain, the teleconnections seen within Fig. 3b could be tested. If validated, then the entire SOM analysis presented here is also supported since the same physics and assumptions underlie both the site-specific and domainwide analyses. Our SOM methods and analyses could also be applied to a broader spatial domain, especially as computational speed increases, that would incorporate additional paleoclimate study sites. Similarly, the methods and analyses here could be applied to longer temporal periods, such as the results of a paleoclimate weather model run over the length of the core period. Both of these extensions could be compared to our results for further validation. For the purpose of this discussion, however, we assume that our results do have some relevancy to paleoclimate, as noted in the first paragraph, and point out some of the major linkages.

In terms of core proxy interpretation, one relevant finding (beyond the obvious that winters are long and cold) is that in summer advected air tends to come from the south and west and in winter advected air tends to come from the north and east, as this may relate to isotopic and other chemical indicators of provenance; that is, wind-blown or affected proxies indicating an origin in the south could perhaps also now be used as indicators of warmer weather. Given that winters dominate the mean annual air temperatures here, winters also have the largest potential for variation. We found very little change in summer temperatures over the past $50 \mathrm{yr}$, but we did find an increase in winter's negative degree-days by an amount greater than the total mean summer positive degree-days. Thus, all else being equal, when interpreting proxy temperatures for mean annual temperatures, the freezing season, and in particular the shoulder seasons of spring and autumn, should be considered as the most likely source of variation.

We also found that weather patterns here seem relatively stable with time, showing little change in frequency compared with changes in what those patterns bring with them. Given that some of the largest changes in global temperature in the past few thousand years have occurred during this 50-yr interval, we have some confidence that the range of weather patterns that existed during this interglacial and many recent ones is captured by those of the past $50 \mathrm{yr}$ and that their frequency during interglacials was likely similar. Thus, when interpreting air temperatures changes here in prior interglacials, based on this analysis one should probably look to changes in thermodynamics first rather than a shift in frequency of storm tracks.

We found that nearly all of the warming observed occurred during spring and fall, while air temperatures were still below $0^{\circ} \mathrm{C}$. We found little change in summer itself, in terms of degree-days or frequency, despite the large rise in mean annual temperature; our results therefore offer no suggestion that paleo-summers were hotter but rather that they were longer or shorter, as this may impact core proxy interpretations, particularly those that have temperature-thresholds or thaw-season length-thresholds like vegetative growth. Modern fall weather patterns are getting warmer primarily 
through the variations of typical summer patterns that occur in fall. These patterns are not getting more frequent, but rather the source area for wind advection is getting warmer. In this case, the source area is largely from the southwest from continental Russia. However, nearly all patterns showed warming, with wind therefore coming from every direction, and confusing things further is that our methods do not distinguish advected warming from local warming. So the picture of warming here is less clear than the warming that Alaska experienced after 1976, and therefore proxy interpretations will require some care when evaluating our work relative to source area effects of proxies.

We believe our results also provide useful indications of how representative Lake El'gygytgyn is to its surroundings in the modern and paleoenvironment. Aleutian low pressure systems dominate winter weather across Beringia, with its influence stretching deep in to Russia and Canada. Lake El'gygytgyn weather, including winds and air temperature, is also dominated by these low pressure systems. Figure $3 \mathrm{~b}$ clearly shows these patterns, coupled with strong high pressure in the Beaufort and Chukchi Seas, which tend to bring anomalously warm/cold air to Lake El'gygytgyn, also bring warm/cold air to elsewhere in Siberia, Alaska, and Canada, though individual patterns show different, but predictable, responses. The general dynamic within the domain is similar to that of Lake El'gygytgyn, which is that the largest temperature anomalies (both warm and cold) occur in winter, as seen in the patterns on the lower row and right sides of Fig. 3b. Note that this is not to say that the Lake El'gygytgyn region is representative of weather in Alaska, only that winter shows substantially more variability than summer in both. Indeed, most strong negative temperature anomalies at the lake are associated with strong positive temperature anomalies elsewhere in the domain, and vice versa. While it is clear that there is substantial spatial variability in climate and its trends within this domain, the differences are not random and our analyses have shown a way to deconstruct it and apply it to larger spatial or temporal domains for further testing.

Acknowledgements. This work was supported by NSF Grant EAR-0602512; note that any opinions, findings, and conclusions or recommendations expressed in this paper are those of the authors and do not necessarily reflect the views of the National Science Foundation, other funding sources, or any of the other team members. We wish to thank the Lake El'gygytgyn science team for their support and numerous discussions about this project. We also thank three anonymous reviewers for their useful comments and suggestions.

Edited by: J. Brigham-Grette

\section{References}

Brigham-Grette, J., Melles, M., Minyuk, P., and Party, S.: Overview and significance of a $250 \mathrm{ka}$ paleoclimate record from El'gygytgyn Crater Lake, NE Russia, J. Paleolimnol., 37, 1-16, 2007.

Cassano, E. N., Cassano, J., and Nolan, M.: Synoptic weather pattern controls on temperature in Alaska, J. Geophys. Res., 116, D11108, doi:10.1029/2010JD015341, 2011.

Cassano, E. N., Lynch, A. H., Cassano, J. J., and Koslow, M. R.: Classification of synoptic patterns in the western Arctic associated with extreme events at Barrow, Alaska, USA, Clim. Res., 30, 83-97, 2006.

Cassano, J. J., Uotila, P., and Lynch, A. H.: Changes in synoptic weather patterns in the polar regions in the twentieth and twentyfirst centuries, Part 1: Arctic, Int. J. Climatol., 26, 1027-1049, 2006.

Cassano, J. J., Uotila, P., Lynch, A. H., and Cassano, E. N.: Predicted changes in synoptic forcing of net precipitation in large Arctic river basins during the 21st century, J. Geophys. Res., 112, G04S49, doi:10.1029/2006JG000332, 2007.

Cherapanova, M. V., Snyder, J. A., and Brigham-Grette, J.: Diatom stratigraphy of the last $250 \mathrm{ka}$ at Lake El'gygytgyn, northeast Siberia, J. Paleolimnol., 37, 155-162, 2007.

Comiso, J. C.: Warming Trends in the Arctic from Clear Sky Satellite Observations, J. Climate, 16, 3498-3510, doi:10.1175/15200442(2003)016<3498:WTITAF>2.0.CO;2, 2003.

Finnis, J., Cassano, J. J., Holland, M. M., and Serreze, M. C.: Synoptically forced hydroclimatology of major Arctic watersheds in general circulation models, Part 1: the Mackenzie River basin, Int. J. Climatol., 29, 1226-1243, 2009.

Glushkova, O. Y. and Smirnov, V. N.: Pliocene to Holocene geomorphic evolution and paleo-geography of the El'gygytgyn Lake region, NE Russia, J. Paleolimnol., 37, 37-47, 2007.

Hewiston, B. C. and Crane, R. G.: Self-organizing maps: applications to synoptic climatology, Clim. Res., 22, 13-26, 2002.

Juschus, O., Pavlov, M., Schwamborn, G., Federov, G., and Melles, M.: Lake Quarternary lake-level changes of Lake El'gygytgyn, NE Siberia, Quarternary Res., 76, 441-451, 2011.

Kalnay, E., Kanamitsu, M., Kistler, R., Collins, W., Deaven, D., Gandin, L., Iredell, M., Saha, S., White, G., Woollen, J., Zhu, Y., Leetmaa, A., and Reynolds, R.: The NCEP/NCAR 40 year reanalysis project, B. Am. Meteorol. Soc., 77, 437-471, 1996.

Kohonen, T.: Self-organizing maps, Springer, New York, 2001.

Layer, P.:Argon-40/Argon-39 age of the El'gygytgyn impact event, Chukotka, Russia, Meteorit. Planet. Sci., 35, 591-599, 2000.

Lindsay, R. W. and Zhang, J.: The Thinning of Arctic Sea Ice, 19882003: Have We Passed a Tipping Point?, J. Climate, 18, 48794894, doi:10.1175/JCLI3587.1, 2005.

Lynch, A. H., Uotila, P., and Cassano, J. J.: Changes in synoptic weather patterns in the polar regions in the twentieth and twentyfirst centuries, Part 2: Antarctic, Int. J. Climatol., 26, 1181-1199, 2006.

Melles, M., Minyuk, P., Brigham-Grette, J., and Juschus, O.: The Expedition to El'gygytgyn Lake 2003 Potsdam, Ber. Polarforsch. Meeresforsch., 1-509, 2005. 
Melles, M., Brigham-Grette, J., Glushkova, O. Y., Minyuk, P. S., Nowaczyk, N. R., and Hubberten, H. W.: Sedimentary geochemistry of core PG1351 from Lake El'gygytgyn - a sensitive record of climate variability in the East Siberian Arctic during the past three glacial-interglacial cycles, J. Paleolimnol., 37, 89-104, 2007.

Minyuk, P. S., Brigham-Grette, J., Melles, M., Borkhodoev, V. Y., and Glushkova, O. Y.: Inorganic geochemistry of El'gygytgyn Lake sediments (northeastern Russia) as an indicator of paleoclimatic change for the last $250 \mathrm{kyr}$, J. Paleolimnol., 37, 123-133, 2007.

Nolan, M.: Quantitative and qualitative constraints on hind-casting the formation of multiyear lake-ice covers at Lake El'gygytgyn, Clim. Past, 9, 1253-1269, doi:10.5194/cp-9-1253-2013, 2013.

Nolan, M. and Brigham-Grette, J.: Basic hydrology, limnology, and meteorology of modern Lake El'gygytgyn, Siberia, J. Paleolimnol., 37, 17-35, 2007.
Nolan, M., Liston, G., Prokein, P., Brigham-Grette, J., Sharpton, V., and Huntzinger, R.: Analysis of Lake Ice Dynamics and Morphology on Lake El'gygytgyn, Siberia, using SAR and Landsat, J. Geophys. Res., 108, D28162, doi:10.1029/2001JD000934, 2002.

Reusch, D. B., Hewitson, B. C., and Alley, R. B.: Towards ice corebased synoptic reconstructions of West Antarctic climate with artificial neural networks, Int. J. Climatol., 25, 581-610, 2005.

Serreze, M. C., Barrett, A. P., Stroeve, J. C., Kindig, D. N., and Holland, M. M.: The emergence of surface-based Arctic amplification, The Cryosphere, 3, 11-19, doi:10.5194/tc-3-11-2009, 2009.

Schuenemann, K. and Cassano, J. J.: Changes in synoptic weather patterns and Greenland precipitation in the 20th and 21st centuries, Part 2: Analysis of 21st century atmospheric changes using self-organizing maps, J. Geophys. Res., 115, D05108, doi:10.1029/2009JD011706, 2010. 